\title{
Metastatic thyroid C-cell carcinoma in a beagle dog
}

\author{
So-ra Lee ${ }^{1}$, Mi-kyoung Lee ${ }^{1}$, Kyoung-a Youp ${ }^{1}$, Ah-ra Lee ${ }^{1}$, Sung-jun Won ${ }^{1}$, Myung-chul Kim ${ }^{2}$, \\ So-yeon Kim ${ }^{2}$, Yongbaek Kim ${ }^{2,3, *}$ \\ ${ }^{1}$ Irion Animal Hospital, Seoul 135-100, Korea \\ ${ }^{2}$ The Laboratory of Clinical Pathology and \\ ${ }^{3}$ Research Institute for Veterinary Research, College of Veterinary Medicine, \\ Seoul National University, Seoul 151-742, Korea \\ (Received: April 5, 2013; Revised: July 1, 2013; Accepted: July 18, 2013)
}

\begin{abstract}
An adult beagle dog was presented with a cervical mass detected by palpation and computed tomography. Fine needle aspirates revealed numerous epithelial cells with plasmacytoid appearance and frequent naked nuclei. Histologically, the mass consists of multiple packets of neoplastic cells and extensive areas of necrosis and fibrosis. Neoplastic cells were also found in submandibular lymph nodes. Immunohistochemistry showed that neoplastic cells were positive for calcitonin and negative for thyroglobulin. Based on these findings, the cervical mass was diagnosed as thyroid C-cell carcinoma. Almost one year after the surgical excision, the dog remains healthy without any symptom of recurrence or metastasis.
\end{abstract}

Keywords : calcitonin, C-cell carcinoma, dog, metastasis, thyroid

Tumors of thyroid gland are relatively common and accounts for 1.2 to $3.8 \%$ of all canine tumors [9]. In dogs malignant thyroid tumors are more common than benign tumors and can arise from either follicular or parafollicular cell lineages [6]. Generally, canine thyroid C-cell carcinomas are more encapsulated and less invasive than thyroid adenocarcinomas. Compared to thyroid adenocarcinomas, canine thyroid C-cell carcinomas carry a more favorable prognosis. Because prognosis of thyroid tumors in the dogs is different for each subtype, determination of their subtype is important [5]. The present report describes the clinical, morphologic and immunohistochemical features of a thyroid Ccell carcinoma occurred in a beagle dog.

An 11-year-old female beagle dog weighing $9.8 \mathrm{~kg}$ was presented to the Irion Animal Hospital, Seoul, South Korea for several-year history of intermittent facial nerve paralysis. On physical exam, the dog was overweight with a body score of $4 / 5$. Palpation revealed a mass on neck region. Computed tomography (CT) was performed in order to characterize the anatomic location of the cervical mass in association with surrounding tissue. CT revealed a heterogeneous, peripherally contrast-enhanced, ellipsoidal and lobulated mass, 42.3 $\mathrm{mm} \times 13.7 \mathrm{~mm} \times 10.0 \mathrm{~mm}$ in size, adjacent to the common carotid artery and the trachea (Fig. 1). Radiography showed bilateral degenerative arthritis in stifle joints. Complete blood counts, serum chemistry, and urinalysis were carried out and

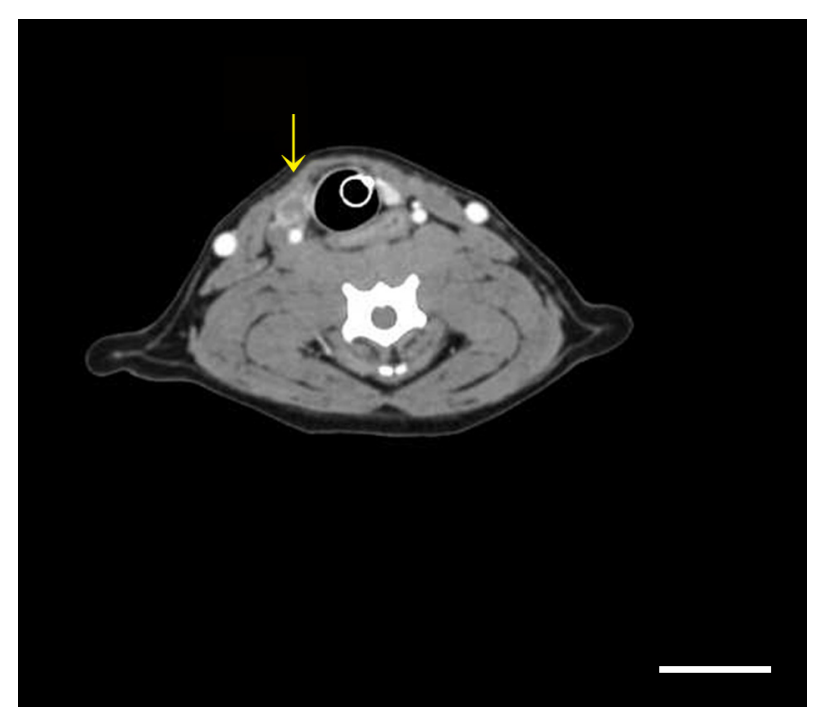

Fig. 1. Computed tomography examination revealed a heterogeneous, ellipsoidal and lobulated mass (arrow), $42.3 \mathrm{~mm} \times$ $13.7 \mathrm{~mm} \times 10.0 \mathrm{~mm}$ in size, with peripheral contrast enhancement is present adjacent to the common carotid artery and the trachea. Scale Bar $=10 \mathrm{~cm}$.

the results were unremarkable except calcium level in the upper margin $(11.8 \mathrm{mg} / \mathrm{dL}$, reference interval: $7.9 \sim 12.0 \mathrm{mg} /$ dL). Total T4, free T4 and thyroid stimulating hormone lev-

*Corresponding author

Tel: +82-2-880-1273, Fax: +82-2-873-1213

E-mail: yongbaek@snu.ac.kr 


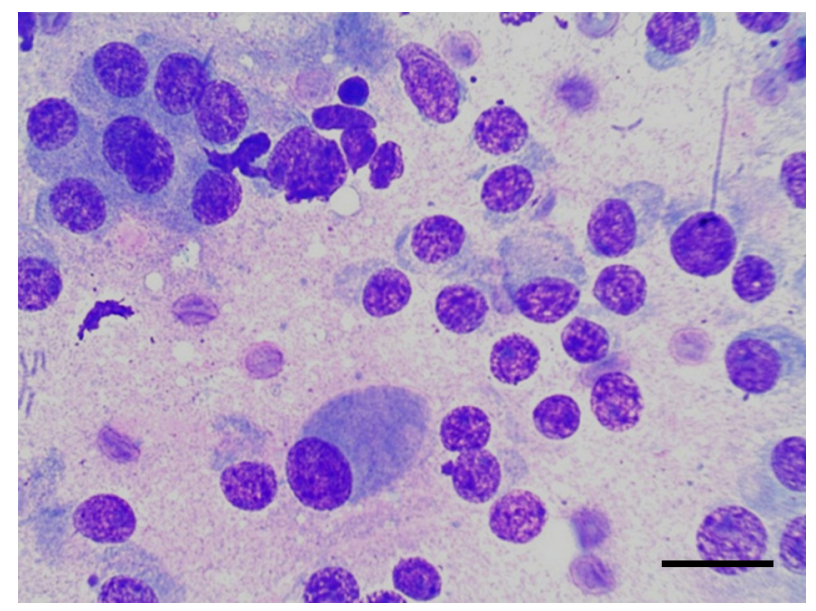

Fig. 2. Fine-needle aspirate of a cervical mass in a dog. Smears of the FNA showed moderate to high cellularity composed of small clusters of cells and individualized cells. Cells with naked nuclei were frequently observed. Occasional cells exhibited plasmacytoid morphology with abundant, basophilic granular cytoplasm and an eccentrically located nucleus with multiple prominent nucleoli and coarse chromatin pattern. Anisocytosis and anisokaryosis of the neoplastic cells were moderate. Amorphous to granular basophilic material is present in the background. Diff Quik stain. Scale Bar $=40 \mu \mathrm{m}$.

els were within the reference interval.

Cytology samples were obtained by fine needle aspiration (FNA) from the cervical mass, smeared on glass slides, air dried and stained with Diff-Quick. Smears of the FNA had moderate cellularity with small clusters of cells as well as individualized cells. Frequent cells had plasmacytoid morphology with abundant, basophilic cytoplasm and an eccentrically located nucleus with coarse chromatin pattern (Fig. 2). These cells exhibited moderate anisocytosis, anisokaryosis and multiple prominent nucleoli. In some cells, metachromatic cytoplasmic granules were evident. Individualized cells with naked nuclei were also observed (Fig. 2). Amorphous to granular eosinophilic material was present in the background.

The cervical masses were surgically excised, fixed in $10 \%$ neutral buffered formalin, and sent to a commercial diagnostic laboratory (The IDEXX laboratory, USA). The tissues were routinely processed, embedded in paraffin, sectioned at $4 \mu \mathrm{m}$, and stained with hematoxylin and eosin for microscopic examination. Histologically, the mass was partially necrotic and had unencapsulated neoplastic tissue that comprised of multiple packets of neoplastic epithelial cells separated by delicate fibrovascular stroma (Fig. 3). In some areas, the neoplastic packets were adjoined by a mild to moderate desmoplastic response and abundant fibrovascular stroma. The neoplastic cells had round to oval vesicular nuclei with 1 or 2 prominent nucleoli. Mitotic figures were present in low numbers (3 to 4 per 10 high-power fields). The neoplastic cells had moderate amounts of amphophilic cytoplasm with

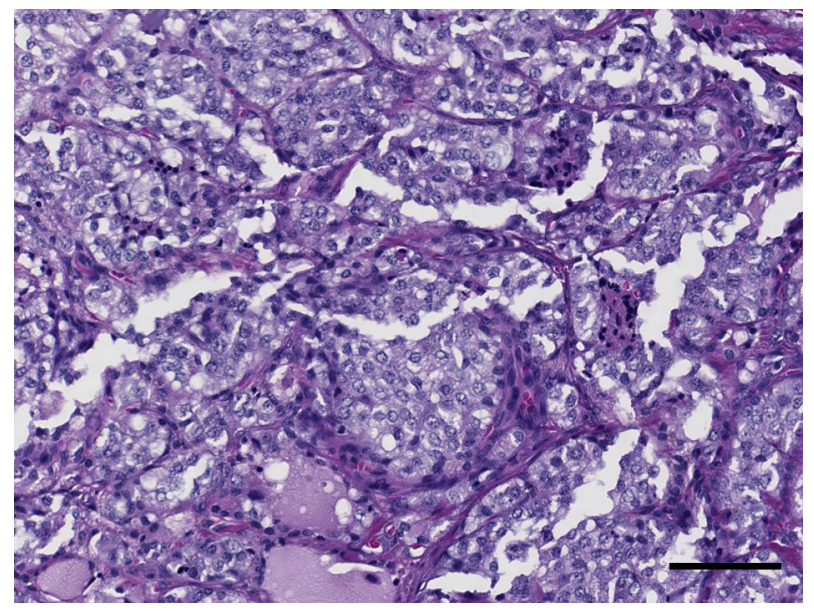

Fig. 3. Histopathology of the cervical mass from a beagle dog. The mass was primarily composed of neoplastic nests or lobules separated by delicate fibrovascular stroma. Occasional thyroid follicles filled with colloid material were interspersed in the neoplastic tissue. H\&E. Scale Bar $=250 \mu \mathrm{m}$.

indistinct borders. In some areas colloid-filled thyroid follicles were intermingled with the packets of neoplastic epithelial cells. The normal architecture of a submandibular lymph node was completely effaced by metastatic tumor tissue similar to the described.

Based on the location and morphological features, differential diagnoses of thyroid adenocarcinoma, thyroid C-cell carcinoma, carotid body chemodectoma, parathyroid carcinoma and other plasmacytoid neoplasm were included. In order to determine the origin of the neoplastic cells, immunohistochemistry (IHC) was performed on the replicate sections of the mass. Primary antibodies used for the IHC were $0.8 \mu \mathrm{g}$ / $\mathrm{mL}$ thyroglobulin (catalog no. A0251; Dako, USA) diluted in casein (catalog SP-5020; Vector Laboratories, USA) and 0.3 $\mu \mathrm{g} / \mathrm{mL}$ calcitonin (catalog no. A0576; Dako) diluted in casein. Primary antibodies were incubated for $30 \mathrm{~min}$ at room temperature. Neoplastic cells were positive for calcitonin (Fig. 4) and were negative for thyroglobulin (Fig. 5). The IHC findings led to the diagnosis of thyroid C-cell carcinoma and clearly ruled out thyroid adenocarcinoma and other tumor types.

Thyroid C-cell carcinomas, also known as parafollicular or C-cell thyroid carcinomas represent $36 \%$ of all thyroid carcinomas in a retrospective study of 38 cases of canine thyroid neoplasms, and have a slightly different gross appearance and prognosis compared to thyroid adenocarcinomas [5]. Cytologically, thyroid adenocarcinomas are composed of a fairly uniform population of neoplastic epithelial cells characterized by a round to polygonal shape, moderate amount of basophilic cytoplasm containing small clear vacuoles and/or rare blue/black granules, moderate to high nucleus to cytoplasm ratio, and medium to large round nuclei with granular to clumped chromatin [2]. Clusters or sheets of epithelial cells are typically seen and often contain amorphous eosino- 


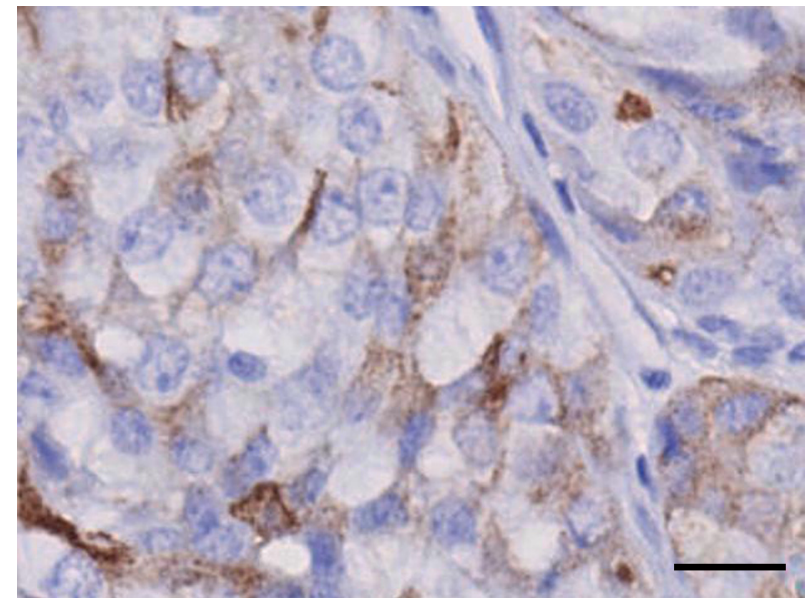

Fig. 4. Immunohistochemistry of the cervical mass from a beagle dog. Note the positive staining for calcitonin in the cytoplasm of the neoplastic cells. Immunohistochemistry and hematoxylin. Scale Bar $=50 \mu \mathrm{m}$.

philic material suggestive of secretory function. Anisocytosis and anisokaryosis are generally moderate. In contrast, cytology of thyroid C-cell carcinoma is characterized by numerous naked nuclei embedded in a background of paleblue material, typical of neuroendocrine tumors, such as chemodectoma and adrenal pheochromocytoma [3]. Moreover, nuclei of the thyroid C-cell carcinoma are placed eccentrically within the cell and fine eosinophilic granules are often observed within the cytoplasm [2]. The cytologic features of canine thyroid C-cell carcinoma are similar to those of the human counterpart. FNAs of human thyroid C-cell carcinomas consist of individualized or loosely cohesive groups of cells with poorly defined cytoplasmic borders. The nuclei tend to locate eccentrically within the cytoplasm, imparting a plasmacytoid appearance to the tumor cells [7].

Cytologic features of the thyroid C-cell carcinomas could be similar to some cases of follicular and solid adenocarcinomas. Indeed, the cytologic features provided in this case are fairly similar to those provided in a case report of ectopic thyroid follicular carcinoma [4]. Furthermore, solid subtype of thyroid adenocarcinoma may mimic C-cell carcinoma histologically. It is impossible to make a definitive diagnosis based on cytology and histology. It has been well established that a definitive differential diagnosis between thyroid adenocarcinoma and C-cell carcinoma requires immunohistochemistry against thyroglobulin, chromogranin, neuron-specific enolase and calcitonin $[5,8,10]$.

Compared to thyroid adenocarcinomas, canine thyroid Ccell carcinomas are usually well-encapsulated and less invasive and carry a more favorable prognosis [5]. Almost one year after the surgical excision of the cervical mass, the dog remains healthy without any symptom of recurrence or metastasis, which was confirmed by monthly-based physical exam, blood testing and radiologic evaluation. The calcium levels at the high margin could be due to the increased calci-

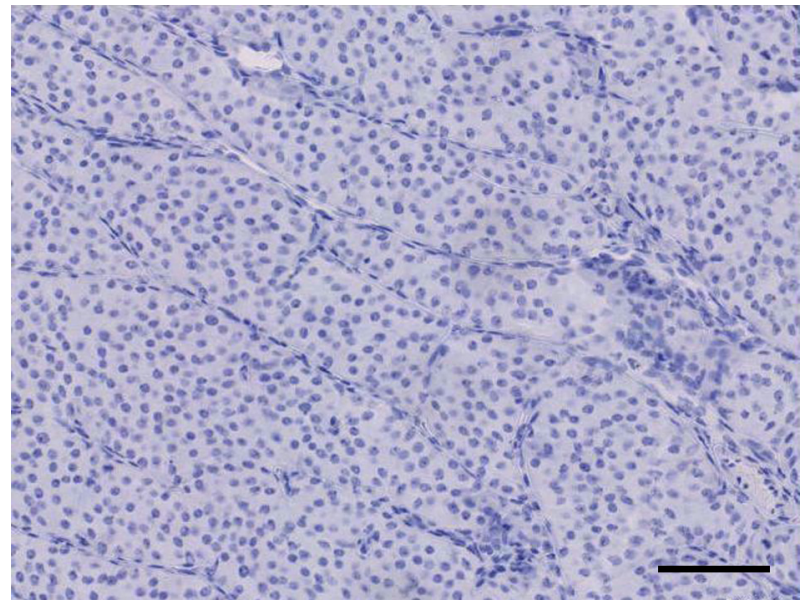

Fig. 5. Immunohistochemistry of the cervical mass from a beagle dog. Negative staining for thyroglobulin in the neoplastic cells. Immunohistochemistry and hematoxylin. Bar $=250 \mu \mathrm{m}$.

tonin produced from the neoplastic cells, reportedly similar to human thyroid C-cell carcinomas [1]. However, the serum calcitonin level in the present case was not evaluated.

In summary, the present case report describes the clinical, cytological, histological, and immunohistochemical features of a metastatic thyroid C-cell carcinoma in a dog with a favorable prognosis following surgical excision.

\section{Acknowledgments}

The authors are grateful to Dr. Rose E. Raskin (Purdue University) for review of the cytopathologic examination.

\section{References}

1. Ahmed SR, Ball DW. Incidentally discovered medullary thyroid cancer: diagnostic strategies and treatment. J Clin Endocrinol Metab 2011, 96, 1237-1245.

2. Alleman AR, Choi US. Endocrine System. In: Raskin RE, Meyer DJ (eds.). Canine and Feline Cytology: A Color Atlas and Interpretation Guide. 2nd ed. pp 383-393, Saunders, St. Louis, 2010.

3. Bertazzolo W, Giudice C, Dell'Orco M, Caniatti M. Paratracheal cervical mass in a dog. Vet Clin Pathol 2003, 32, 209-212.

4. Boes K, Messick J, Green H, Thacker HL, Austin B. What is your diagnosis? Impression smear from an intracardiac mass in a dog. Vet Clin Pathol 2010, 39, 119120.

5. Carver JR, Kapatkin A, Patnaik AK. A comparison of medullary thyroid carcinoma and thyroid adenocarcinoma in dogs: a retrospective study of 38 cases. Vet Surg 1995, 24, 315-319.

6. Leav I, Schiller AL, Rijnberk A, Legg MA, der Kinderen PJ. Adenomas and carcinomas of the canine and feline thyroid. Am J Pathol 1976, 83, 61-122.

7. Matias-Guiu X, DeLellis RA, Moley JF. Medullary 
192 So-ra Lee, Mi-kyoung Lee, Kyoung-a Youp, Ah-ra Lee, Sung-jun Won, Myung-chul Kim, So-yeon Kim, Yongbaek Kim

thyroid carcinoma. In: DeLellis RA, Lloyd RV, Heitz PU, Eng C (eds.). WHO Classification of Tumours: Pathology and Genetics of Tumours of Endocrine Organs. 3rd ed. pp 86-91, IARC, Lyon, 2004.

8. Moore FM, Kledzik GS, Wolfe HJ, DeLellis RA. Thyroglobulin and calcitonin immunoreactivity in canine thyroid carcinomas. Vet Pathol. 1984, 21, 168-173.
9. Page RL. Tumors of the endocrine system. In: Withrow SJ, MacEwen EG (eds.). Small Animal Clinical Oncology. 3rd ed. pp 423-427, WB Saunders, Philadelphia, 2001.

10. Patnaik AK, Lieberman PH. Gross, histologic, cytochemical, and immunohistochemical study of medullary thyroid carcinoma sixteen dogs. Vet pathol 1991, 28, 223-233. 